\title{
Chapter 7 \\ Effects of Formalisation of the Shadow \\ Economy
}

\author{
Milojko Arsić and Gorana Krstić
}

\subsection{Fiscal Implications of Formalisation of Shadow Economy}

\subsubsection{Estimate of Possible Fiscal Effects with Respect to VAT}

As tax evasion is by far the largest component of the VAT gap, the question that needs to be asked is to what extent VAT revenue could be increased by ensuring better tax collection over the medium and the long term, all other considerations being equal. ${ }^{1}$ Over the medium term a realistic aim for Serbia would be to reduce the VAT gap to the average level seen in the five new Central European EU member states before their EU accession. This means that in the next several years a realistic aim would be to cut the VAT gap from its current level of $21 \%$ to $18-19 \%$, as experienced by Central European EU member states. Cutting the VAT gap by 2-3 percentage points would result in an increase in the Serbian budget revenues of between 0.2 and $0.5 \%$ of GDP. In the long run, say within 10 years, Serbia could aim to reduce the VAT gap to the EU average of $13.5 \%$. Cutting the VAT gap to this level, all other conditions being equal, would increase budget revenue by $1 \%$ of GDP. Hypothetically, if Serbia's VAT gap were reduced to the level seen by the

\footnotetext{
${ }^{1}$ It is important to bear in mind that other factors, such as a re-orientation of the economy towards exports (not subject to VAT) and greater investment (subject to lower VAT rates), will have an impact on the reduction of both hypothetical and actual VAT revenue. In this context any estimate of additional revenues due to a reduction in the VAT gap should be treated as a hypothetical estimate, all other conditions being equal, rather than as a realistic one. Closing the VAT gap is therefore a necessary precondition for preventing, or at least reducing, any future decline in the ratio of VAT revenue to GDP.
}

M. Arsić $(\varangle)$ • G. Krstić

Faculty of Economics, University of Belgrade, Belgrade, Serbia

e-mail: arsicm@ekof.bg.ac.rs; gkrstic@ekof.bg.ac.rs 
five most efficient EU members (Finland, Sweden, Ireland, Luxembourg, and France), where it stands at a mere $5 \%$, the additional revenue would be $2 \%$ of GDP.

All of the above estimates were made using current VAT rates as of 2011; we therefore ought to determine the effect on these estimates of the increase in the general VAT rate from 18 to $20 \%$ that took effect in late 2012. The rise in the general tax rate by 2 percentage points, as well as other changes to the VAT system, will result in an increase in the potential VAT revenues of some RSD 33 billion at current prices, which equals about $1 \%$ of GDP. However, given the existing tax gap (i.e. if the shadow economy remains unchanged), actual VAT revenues will increase by about RSD 25 billion, or about $0.8 \%$ of GDP (Fiscal Council 2012). ${ }^{2}$

\subsubsection{Estimate of Possible Fiscal Effects with Respect to Personal Income Tax and Social Contributions}

Although the overall personal income tax and social contributions gap is relatively significant, as we have seen in Chap. 5, potential additional public revenues that could be generated through the efficient implementation of measures for reducing the shadow economy are far lower. Even with the efficient use of well-designed measures to combat the shadow economy, and given an effective institutional framework, the shadow economy cannot be reduced to zero-as is borne out by the fact that it is not insignificant even in the most developed countries. According to 2011 estimates the total extent of the shadow economy in EU countries is $19.7 \%$ of GDP (Schneider 2011). Although separate estimates of the shadow economy in household income and consumption are not provided, theoretical and empirical studies have shown that the extent of the shadow economy is greater in income than in consumption. We can accordingly assume that the shadow economy in household income is more widespread than the EU average. Starting from the assumption that the estimated level of the shadow economy in household income in Serbia is $24.4 \%$ of GDP, measures aimed at tackling the shadow economy could reduce this level by some 10-15\%, with a similar reduction in the relevant tax gap. The government would then see an increase of at most $0.6-0.9 \%$ of GDP in income tax and social contributions revenue $(0.6 \%$ of GDP in the medium term and slightly more in the long run, assuming systemic measures are implemented consistently).

Taking into account VAT, income tax, and social contributions, reducing the shadow economy to the level present in other Central and Eastern European countries-an outcome that can be achieved in a relatively short span of time (1-3 years), assuming the adoption and consistent implementation of systemic

\footnotetext{
${ }^{2}$ These estimates differ from those made by the Fiscal Council because the impact on liquidity of the shift to VAT payment upon collection of accounts receivable for small and medium-sized businesses has been ignored, as this is a short-term effect.
} 
Table 7.1 Estimate of the fiscal effects of formalising the informal economy in Serbia (in \% of GDP)

\begin{tabular}{l|l|l}
\hline & Short and medium term (1-3 years) & Long term (7-10 years) \\
\hline VAT & $0.2-0.5$ & 1.0 \\
\hline Income tax and contributions & 0.6 & 0.9 \\
\hline Total & $0.8-1.1$ & 1.9
\end{tabular}

Source: Own calculations

measures - could result in an increase in public revenue of between 0.8 and $1.1 \%$ of GDP (Table 7.1). Reducing the shadow economy to the EU average would take longer (between 7 and 10 years) and require not only institutional measures, but also other structural changes to the Serbian economic system. It could, however, ensure additional public revenue of up to $1.9 \%$ of GDP.

In interpreting the above estimates we must bear in mind that they reflect only the isolated impact of the formalisation of the shadow economy, and not the impact of other factors on the collection of tax revenue. In this sense the estimates presented in Table 7.1 are not a forecast of changes in tax revenue in relation to GDP. Other factors that will affect tax collection include long-term macroeconomic trends such as movements in domestic demand and GDP and changes to the employment rate. Thus, when estimating actual tax revenues, other factors need to be taken into account in addition to the possible formalisation of the shadow economy. The reduction in the difference between domestic demand and GDP, which is necessary to avoid a balance of payments crisis, will cause a substantial drop in VAT revenue in relation to GDP. A 5 percentage point drop in the ratio of domestic demand to GDP would cause a corresponding fall in VAT revenue of about $1 \%$ of GDP. In this context, tackling the shadow economy can be interpreted as a necessary activity to prevent a drop in VAT revenue in relation to GDP, rather than as a possible source of additional tax revenue. In other words, if the shadow economy is not formalised VAT revenue will decline by about 1 percentage point in relation to GDP over the coming several years. Similarly, movements in the actual levels of tax and social contribution revenues in relation to GDP will be affected by changes in the employment rate. The number of employed might decline in 2013, which could, all other things being equal, bring a drop in social contributions and income tax revenue. However, employment in Serbia could increase in the medium and the long term, which would generate additional income tax and social contributions revenue.

\subsection{Effects of Formalising the Shadow Economy on Economic Growth}

The preceding section estimated the possible fiscal effects given certain assumptions of a possible reduction in the shadow economy. This section will attempt to consider how formalising the shadow economy can affect economic growth. This 
question is far more difficult to answer, as although there is a large body of empirical research on the impact of the shadow economy on economic growth, there are still no unequivocal empirical and theoretical findings (Schneider and Enste 2000). The basic question is this: Is the shadow economy, from an economic point of view, a positive phenomenon; in other words, does it make a positive contribution to economic growth? The answer to this question will result in two possible avenues of approach for government policy on the shadow economy: tolerance or active suppression.

We can generally distinguish between three situations:

- Shadow and formal economies are substitutes for one another: any increase in the shadow economy leads to a reduction in the volume of the formal economy;

- The volume of the formal economy is a given (i.e., fixed): the shadow economy increases the total economic activity of a country; and

- The shadow economy contributes to the growth of the formal sector: its effect is multiplicative.

The first view is the conventional one, based on a simple neoclassical model, that the total volume of economic activity in a country is a given, based on the assumption of full factor employment, so that the shadow economy may grow only at the expense of economic activity in the formal sector. According to this position, an entity chooses whether to take part in the shadow or the formal economy; not doing business (being unemployed) is not an option. In this case total GDP will even decrease, as operating efficiency is lower in the shadow than in the formal economy (less capital-intensive technologies, greater uncertainty, poorer protection of owners' rights, etc.). Loayza (1996) showed how, under certain conditions and using the example of Latin American countries, excessive tax burden and over-regulation encourage the growth of the informal sector, which has a negative impact on the pace of overall economic growth.

In the second case, given an unfavourable institutional environment, the volume of activity in the formal economy may be a given; i.e., adverse circumstances may preclude full-factor employment in this sector. For example, prohibitive laws, poor economic policies, sanctions, or wars may constrain growth, as was the case with Serbia in the 1990s. In this situation growth in the shadow economy does not affect the formal sector but rather leads to an increase in the total economic activity.

Finally, in the third case, the shadow economy can have a positive impact on economic activity in the formal sector through the interaction of the two sectors. According to empirical research carried out by Schneider (1999), two-thirds of income earned in the shadow economy in Germany and Austria is spent on consumption in the formal economy (where value-added tax is payable), thus boosting formal sector growth. The UK also saw a similar stimulating effect of the informal economy on consumption in the formal sector (Bhattacharyya 1999).

An answer to the question of whether the shadow economy is useful or not and how it affects economic growth can be found by using econometric models which will be presented below. However, in real life various models and factors can act 
together, usually in opposing directions, and have different impacts on the final result.

It can be posited that any major reduction in the shadow economy leads to a major increase in tax revenue, which leads to more and better public goods and services, which in turn boosts economic growth. This hypothesis was empirically confirmed by, among others, Loayza (1996), whose research covered Latin America. He established that any growth in the relative volume of the shadow economy (in percent of GDP) contributes to a reduction in the growth of official GDP in countries where (a) the statutory tax burden is greater than the optimum and where (b) enforcement of compliance is too weak. This negative impact on GDP can be explained by (a) reduced availability of public services in the formal sector and (b) lower efficiency of the use of existing public services. The foundations of this model have been criticised (Asea 1996), while the assumption that the shadow economy hurts economic growth has failed to find widespread acceptance.

In the case of transition countries, Kaufmann and Kaliberda (1996) estimated that the shadow economy has cushioned the drop in registered GDP, particularly in countries that faced major declines in their GDP levels. Over half of the decline in registered GDP carried over into the drop in overall economic activity, while the other half was absorbed by the growing shadow economy. Using Ordinary Least Squares regression, they concluded that the share of the shadow economy in overall GDP increased by nearly $4 \%$ for each $10 \%$ of cumulative decline in registered GDP.

Eilat and Zinnes (2000) came to a very important conclusion applicable to transition economies, showing that there is an inertia effect in the creation of the shadow economy, as well as a hysteresis effect in its destruction. If overall economic activity is on the decline, a drop in GDP of one dollar is linked to an increase in the shadow economy by 31 cents, meaning that the shadow economy cushions the fall of registered GDP. On the other hand, if overall economic activity is on the increase, a one-dollar rise in GDP leads to a reduction of just 25 cents in the shadow economy. These findings indicate that caution is necessary when estimating the effects of formalising the shadow economy on economic growth.

According to Schneider (2004), the shadow economy hurts economic growth in developing countries while having a positive effect on economic growth in developed countries. The results of this econometric analysis, which covered 21 OECD member states and 89 developing and transition countries, show that in developed economies an increase in the shadow economy of 1 percentage point of GDP leads to an increase in registered GDP of $7.7 \%$. On the other hand, in developing countries 1-percentage-point growth in the shadow economy leads to a $4.9 \%$ drop in registered GDP, all other model variables being equal (openness of the economy, inflation, government spending, capital accumulation rate, population). One explanation for these results is that growth in the shadow economy in developed countries may stimulate the formal economy by generating additional income that boosts formal-sector consumption. On the other hand, in developing countries a greater volume of the shadow economy leads to a substantial erosion of the tax base, which results in lower availability of public infrastructure and basic public 
services (such as an efficient legal system), in turn causing lower economic growth. We believe that both of these explanations can be relevant to developing and developed countries, but their final effect on economic growth depends on which group of factors dominates.

However, a study carried out by USAID (2005) shows that there is no correlation between the GDP growth rate and the shadow economy, and concludes that no empirical confirmation can be found of the hypothesis that a reduction in the shadow economy automatically leads to economic growth, and vice versa. Although countries with higher GDP per capita have smaller shadow economies, it cannot be determined whether formalisation is the cause or consequence of the higher level of development. The authors also state that the available series of data on changes to the shadow economy are not long enough to confirm or deny the assumption that countries with high rates of economic growth are able to reduce their shadow economy levels faster than those with lower growth rates. When viewed from a theoretical standpoint the shadow economy limits business growth, as it denies companies access to critical services and the opportunity to separate their business and personal assets, which increases risk and constrains growth.

Serbia's experience over a lengthy period of time shows the predominance of distorting and negative effects of the shadow economy on balanced economic growth, particularly in times of economic crisis. In the crisis conditions that Serbia has faced since 2008 the shadow economy has become part of a vicious circle, where one consequence of recession is flight from the formal to the shadow economy, thus reducing tax revenue and thereby the availability of public services and increasing the fiscal deficit. The growing deficit must then be compensated for by greater tax rates, which drive companies and workers into the shadow economy or out of the economy altogether. This downward spiral keeps repeating itself, always at a lower level of GDP and employment. The state receives ever-lower amounts of money to pursue appropriate development policies and finance public services, leading to poorer public services and the continuation of the vicious circle where companies are increasingly less ready to pay taxes. Government bodies are thus faced with the task of adjusting how institutions operate and calibrating economic policies so that the reduction in the shadow economy is accomplished by shifting business from the informal to the formal sector, and so that there is neither a decline in activity nor a drop in GDP.

Results of the study conducted using the MIMIC method in Serbia and the other 10 Central and Eastern European countries shown in Chap. 5 indicate that the impact of the shadow economy on official GDP is statistically highly significant, and has the expected negative sign. Depending on the model used, the value of the GDP per capita coefficient varies between -0.60 and -0.70 , meaning that if GDP per capita declines by 1 percentage point, the shadow economy will grow by between 0.6 and 0.7 percentage points. In other words, if GDP declines in the future the shadow economy will grow as business entities attempt to off-set the limited opportunities for doing business in the formal sector by becoming active in the shadow economy. 
Open Access This chapter is distributed under the terms of the Creative Commons Attribution Noncommercial License, which permits any noncommercial use, distribution, and reproduction in any medium, provided the original author(s) and source are credited.

\section{References}

Asea P (1996) The informal sector: baby or bath water? Carnegie-Rochester Conference Series on Public Policy. 45: 163-171

Bhattacharyya DK (1999) On the economic rationale of estimating the hidden economy. Econ J 109(456):348-359

Eilat Y, Zinnes C (2000) The evolution of the shadow economy in transition countries: consequences for economic growth and donor assistance. CAER II Discussion Paper, No. 83

Fiscal Council (2012) Ocena predloga Zakona o budžetu za 2013. godinu

Kaufmann D, Kaliberda A (1996) Integrating the unofficial economy into the dynamics of post socialist economies: a framework of analyses and evidence. In: Kaminski B (ed) Economic transition in Russia and the new states of Eurasia. M.E. Sharpe, London, pp 81-120

Loayza NV (1996) The economics of the informal sector: a simple model and some empirical evidence from Latin America, vol 45. Carnegie-Rochester Conference Series on Public Policy, Washington, DC, pp 129-162

Schneider F (1999) Der Sozialstaat zwischen Markt und Hedeonismus? In: Lamnek S, Luedtke J (Hrsg.) Otto-von-Freising-Tagungen der Katholischen Universität Eichstätt. Leske Budrich, Opladen

Schneider F (2004) Shadow economies around the World: what do we really know? IAW-Diskussionspapiere 16

Schneider F (eds) (2011) Handbook on the shadow economy. Edward Elgar, Cheltenham

Schneider F, Enste D (2000) Shadow economies: size, causes and consequences. J Econ Lit 38(1):77-114

USAID (2005) Removing barriers to formalization: the case for reform and emerging best practice 